\title{
Nevus of Ota - an intraoral presentation: a case report
}

\author{
Jennifer Maguire ${ }^{1 *}$ and Deborah Holt ${ }^{2}$
}

\begin{abstract}
Background: Nevus of Ota or "oculodermal melanocytosis" is a rare congenital hamartoma of dermal melanocytes causing a blue-gray hyperpigmentation of the eye and surrounding structures. The condition, originally described by Ota and Tanino in 1939, mainly affects the ophthalmic and maxillary divisions of the trigeminal nerve. We describe the first reported case of unilateral oculodermal melanocytosis in a Caucasian woman with oral buccal mucosal involvement. Oral involvement of nevus of Ota is very rare.

Case presentation: A 48-year-old Caucasian woman was referred by the dermatology division to the oral medicine department at the University of Liverpool School of Dentistry with new-onset oral pigmentation to the left buccal mucosa. The patient had a previous diagnosis of oculodermal nevus.

Conclusion: An incisional biopsy of the left buccal mucosa was completed. The report stated that histological and immunohistochemical features were in keeping with a blue nevus, but within the context of the preexisting occulodermal pigmentation, a diagnosis of oculodermal melanocytosis, also known as "nevus of Ota," was made. The patient will be kept under review in the oral medicine department because the progression of the lesion on the left buccal mucosa requires active monitoring owing to the potential for malignant change. The patient also requires regular review in the dermatology and ophthalmology divisions.
\end{abstract}

Keywords: Oral, Pigmentation, Nevus, Ota, Oculodermal, Buccal, Mucosa

\section{Background}

Nevus of Ota or "oculodermal melanocytosis" is a rare congenital hamartoma of dermal melanocytes causing a blue-gray hyperpigmentation of the eye and surrounding structures [1]. Originally described by Ota and Tanino in 1939, it mainly affects the ophthalmic and maxillary divisions of the trigeminal nerve and is most prevalent in the Japanese population, with an incidence reported between $0.2 \%$ and $1 \%$ [2]. Oral involvement of the nevus of Ota is very rare [3]. We describe the first reported case of unilateral oculodermal melanocytosis with oral buccal mucosal involvement in a Caucasian woman. It is important to be aware that nevus of Ota can present orally.

\section{Case presentation}

A 48-year-old Caucasian woman was referred to the oral medicine department at the University of Liverpool School of Dentistry with new-onset oral pigmentation to

\footnotetext{
* Correspondence: jenmag48@hotmail.co.uk; jennifer.maguire@olchc.ie 'Our Lady's Children's Hospital Crumlin, Dublin, Ireland

Full list of author information is available at the end of the article
}

the left buccal mucosa. Her past medical history revealed a diagnosis of "oculodermal nevus." She recalled having pigmentation in her left eye from birth and pigmentation of skin of the left face since the age of 13 years, for which she received laser treatment for cosmetic purposes. The patient also reported annual monitoring of a benign intracranial tumor along with close monitoring by ophthalmology and dermatology divisions. She did not take any regular medications. She did not smoke or consume alcohol. She is single and lives on her own with no dependents. She lives close to her mother, who attended the appointments with her.

On examination, a subtle but diffusely speckled bluish pigmentation was observed to the left midface involving the infraorbital and zygomatic regions. A post-laser therapy yellow hue was noted on the left periorbital skin. Pigmentation of the sclera and conjunctiva was also observed. Intraorally, an inhomogeneous, blue-gray, diffuse hyperpigmentation affecting the entire left buccal mucosa was noted. Mild pigmentation of the left hard palate was also noted (Figs. 1, 2, 3, 4 and 5). 

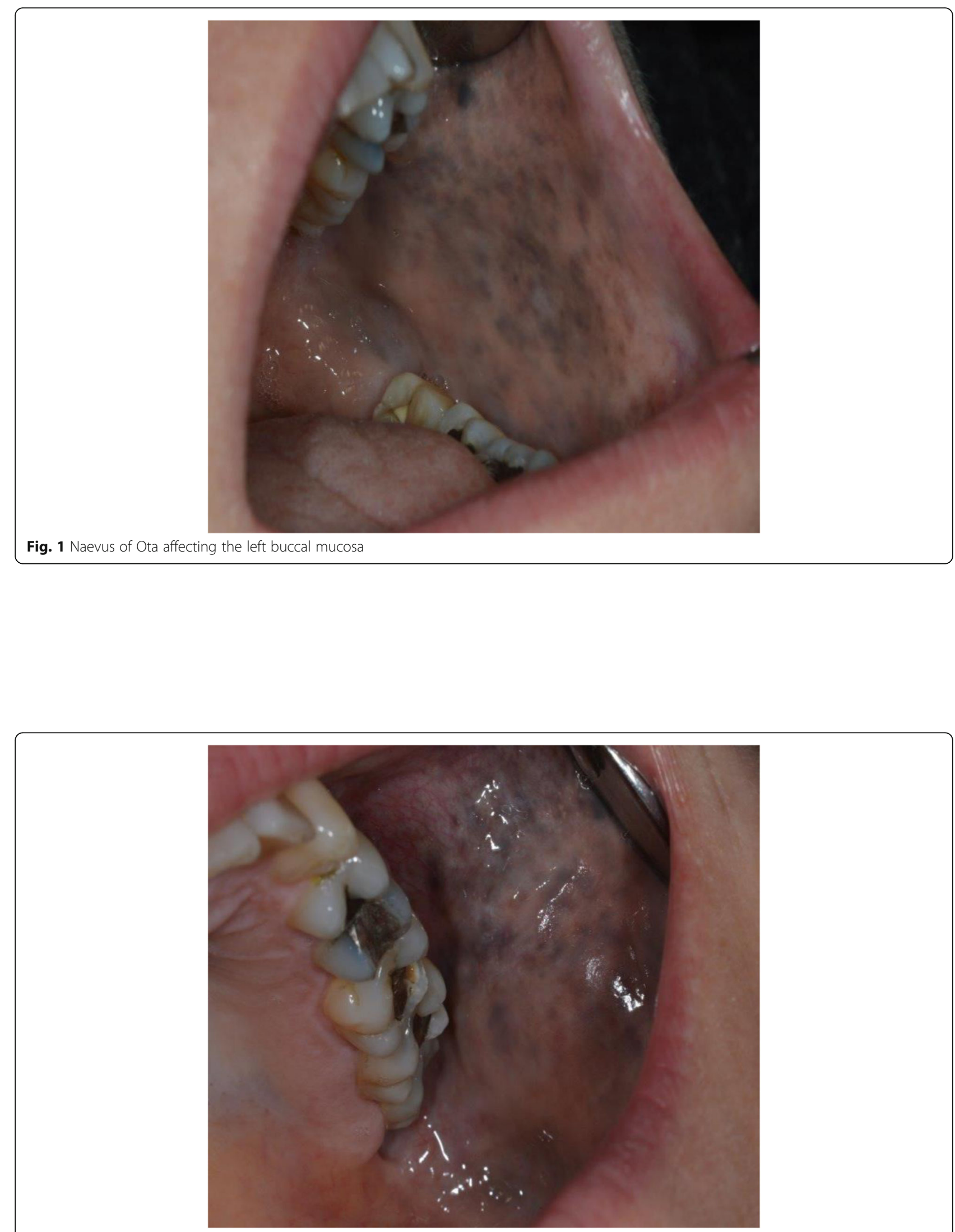

Fig. 2 Naevus of Ota affecting the left buccal mucosa and palate 


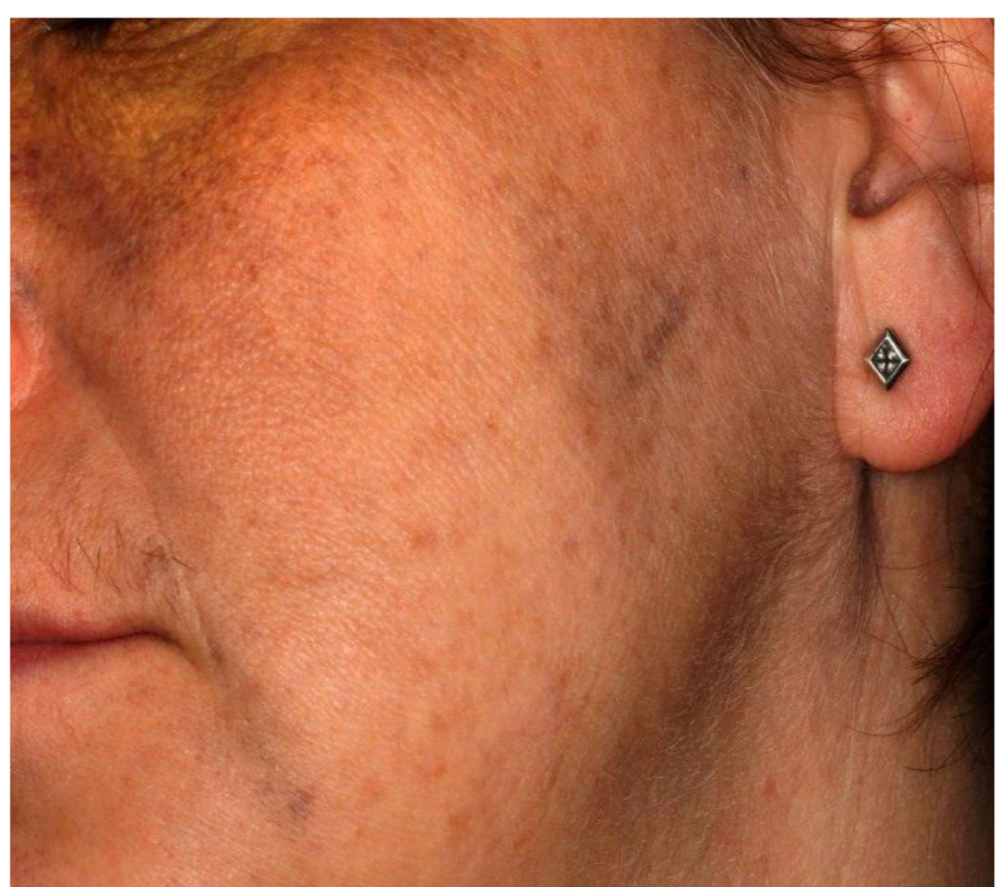

Fig. 3 Naevus of Ota affecting the left Infra-Orbital and Zygomatic region

An incisional biopsy of the left buccal mucosa was completed. The report stated that histological and immunohistochemical features were in keeping with a blue nevus, but within the context of the preexisting occulodermal pigmentation, a diagnosis of oculodermal melanocytosis, also known as "nevus of Ota," was made. No other investigations were required. The patient will be kept under 6-monthly review with the oral medicine department because the progression of the lesion on the left buccal mucosa requires active monitoring owing to the potential for malignant change.

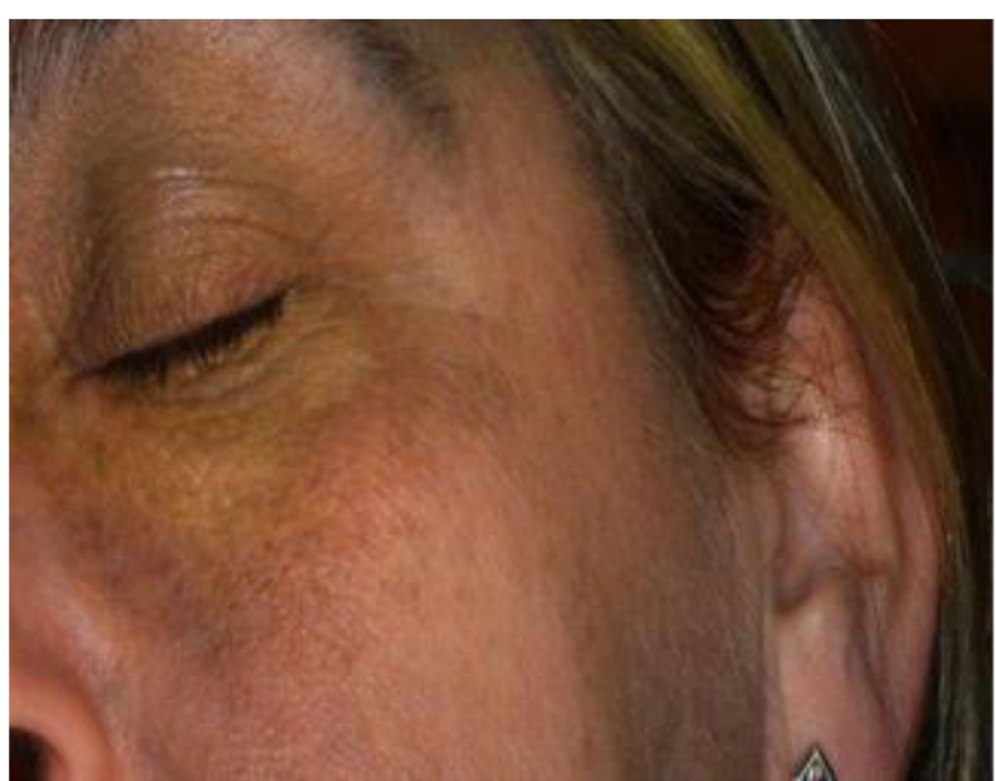

Fig. 4 Post laser scarring in the left Infra-Orbital region 


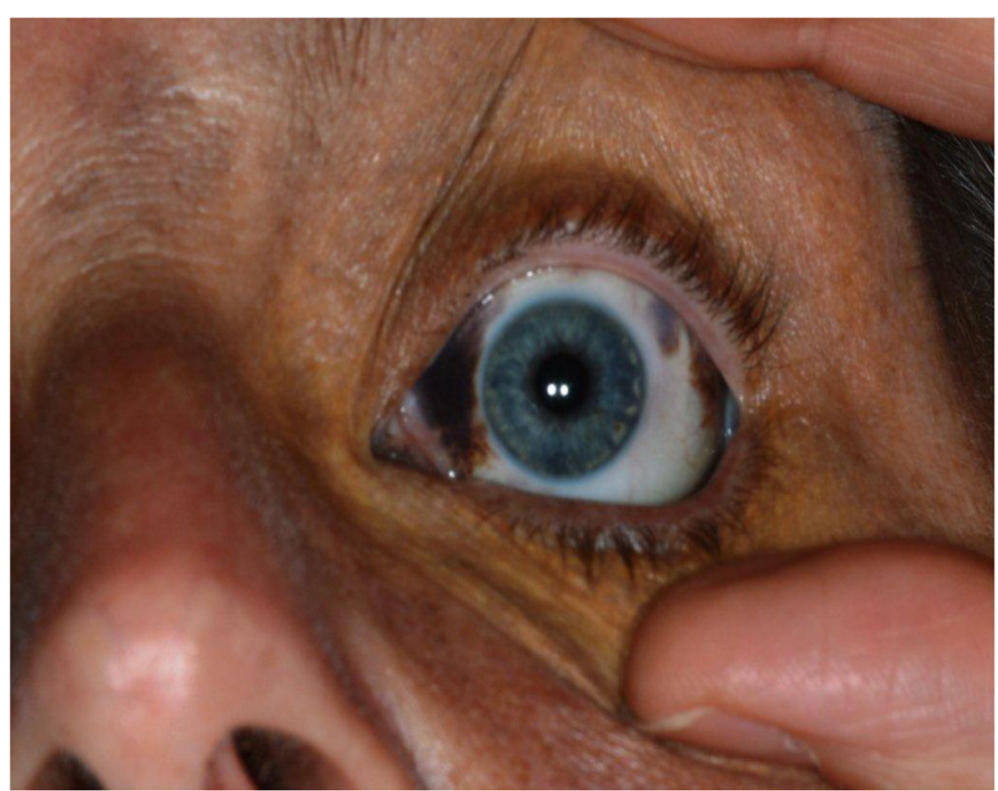

Fig. 5 Naevus of Ota affecting the sclera of the left eye and post laser scarring

\section{Discussion and conclusions}

Nevus of Ota represents a unilateral dermal melanosis in the distribution of the trigeminal nerve, where it is usually confined to the ophthalmic and maxillary divisions. The forehead, temple, periorbital area, cheek, and nose are most commonly involved. Melanin pigmentation involves the eye in about $50 \%$ of cases [4]. Rarely is the pigmentation bilateral with large areas of the face and oral mucous membranes being affected [2].

A literature search of PubMed and Embase revealed only two cases (in India) of nevus of Ota affecting the buccal mucosa $[5,6]$. Intraoral presentations more frequently involve the palatal mucosa.

The prevalence of this condition is greatest in the Asian continent, affecting up to $1 \%$ of the Japanese population [2]. One study has reported an incidence of $0.038 \%$ in Caucasians, although this is poorly documented [7]. About $85 \%$ cases of nevus of Ota occur in females.

Use of lasers for treatment of nevus of Ota has become helpful in the management of dermal nevi. Currently, Q-switched lasers are the most studied, and they have demonstrated positive results for nevus of Ota [8]. Lasers are more effective in light-skinned individuals; however, recurrence can be more common and may result in a darker hue.

Our patient had received laser therapy 20 years earlier and had a good outcome. She has also been referred to the cosmetic camouflage clinic. The patient has seen a makeup artist and uses cosmetics to cover the pigmentation. Long-term follow-up, especially in the ophthalmology division (6-monthly) [9] and neurosurgery division, is required because of the risk of ocular melanoma and central nervous system neoplasia, although this is rare. The patient's intracranial lesion is unrelated to the nevus of Ota. There is also an increased risk of glaucoma associated with nevus of Ota in 10\% of patients [10]. A number of cases of malignant melanoma are also reported in the literature, and careful observation is necessary, particularly in Caucasians, in whom malignant degeneration seems to occur with a disproportionate frequency [11]. It is recommended that these patients be reviewed annually by a dermatologist. It is also of note that there are possible molecular explanations for the risk of malignancy, including mutations of GNAQ and BAP1 genes [12]. This will require further research.

\section{Acknowledgements}

The authors acknowledge Maria Olawale for taking a number of photographs.

Funding

Not applicable.

Availability of data and materials

Not applicable.

\section{Authors' contributions}

JM was involved in assessing the patient, taking photographs, gaining consent, reviewing the literature, and writing the manuscript. DH was the consultant in charge and reviewed the literature. Both authors read and approved the final manuscript.

Ethics approval and consent to participate Not applicable.

\section{Consent for publication}

Written informed consent was obtained from the patient for publication of this case report and any accompanying images. A copy of the written consent is available for review by the Editor-in-Chief of this journal. 


\section{Competing interests}

The authors declare that they have no competing interests.

\section{Publisher's Note}

Springer Nature remains neutral with regard to jurisdictional claims in published maps and institutional affiliations.

\section{Author details}

'Our Lady's Children's Hospital Crumlin, Dublin, Ireland. ${ }^{2}$ Oral Medicine

Department, Liverpool University Dental Hospital, Liverpool, UK.

Received: 9 January 2019 Accepted: 28 April 2019

Published online: 07 June 2019

\section{References}

1. Park JH, Lee MH. Acquired, bilateral nevus of Ota-like macules (ABNOM) associated with Ota's nevus: case report. Korean Med Sci. 2004;19(4):616-8.

2. Gleason CA, Devaskar SU. Initial evaluation: history and physical examination of the newborn. In: Avery's diseases of the newborn. 9th ed. Philadelphia: Elsevier Saunders; 2012. p. 277-99.

3. Bohra A, Bhateja S. Nevus of Ota': a rare oro-facial pigmentation short review. J Pigment Disord. 2015;2:199. https://doi.org/10.4172/ 2376-0427.1000199.

4. Mauropoulos JC, Cohen BA. Disorders of pigmentation. In: Cohen BA, editor. Pediatric dermatology. 4th ed. Philadelphia: Elsevier Saunders. p. 148.

5. Shetty SR, et al. Nevus of Ota with buccal mucosal pigmentation: a rare case. Dent Res J (Isfahan). 2011;8(1):52-5.

6. Mohan RP, et al. 'Nevi of Ota: the unusual birthmarks': a case review. BMJ Case Rep. 2013;2013:bcr2013008648.

7. Gonder JR, et al. Ocular melanocytosis: a study to determine the prevalence of ocular melanocytosis. Ophthalmology. 1982;89(8):950-2.

8. Shah W, Bray FN, Aldahan AS, et al. Lasers and nevus of Ota: a comprehensive review. Lasers Med Sci. 2016;31:179-85.

9. Shields CL, Kaliki S, Livesey M, Walker B, Garoon R, Bucci M, et al. Association of ocular and oculodermal melanocytosis with the rate of uveal melanoma metastasis: analysis of 7872 consecutive eyes. JAMA Ophthalmol. 2013:131:993-1003.

10. Khwaly JA, Imami N, Shields MB. Glaucoma associated with nevus of Ota. Arch Ophthalmol. 1995;113(9):1208-9.

11. Patel CK, et al. Cutaneous malignant melanoma and ocular melanocytosis (nevus of Ota): report of a case and review of the literature. J Am Acad Dermatol. 1998;38(5):862-5.

12. Tse JY, et al. Melanoma arising in a nevus of Ito: novel genetic mutations and a review of the literature on cutaneous malignant transformation of dermal melanocytosis. J. Cutan Pathol. 2016;43(1):57-63. https://doi.org/10.1111/cup. 12568.

Ready to submit your research? Choose BMC and benefit from:

- fast, convenient online submission

- thorough peer review by experienced researchers in your field

- rapid publication on acceptance

- support for research data, including large and complex data types

- gold Open Access which fosters wider collaboration and increased citations

- maximum visibility for your research: over $100 \mathrm{M}$ website views per year

At $\mathrm{BMC}$, research is always in progress.

Learn more biomedcentral.com/submissions 